\title{
Future ethics: risk, care and non-reciprocal responsibility
}

\author{
Christopher Groves* \\ ESRC Centre for Business Relationships, Sustainability and Society (BRASS), \\ Cardiff University, Cardiff, UK
}

\begin{abstract}
As the number of intrinsically unknowable technologically produced risks global society faces continues to grow, it is evident that the question of our responsibilities towards future people is of urgent importance. However, the concepts with which this question is generally approached are, it is argued, deficient in comprehending the nature of these risks. In particular, the individualistic language of rights presents severe difficulties. An alternative understanding of responsibility is required, which, it is argued, can be developed from phenomenological and fe minist concepts of care. Such concepts privilege an understanding of human beings that is primarily relational rather than individualistic, and show that responsibility is, in the first place, about connection rather than respecting separation. Care, by opening up for us an understanding of the diversity of values that are constitutive of a worthwhile life, also connects us to the future as the future of care. As such, it provides us with ethical resources that can guide us in the face of uncertainty, including general principles of action and the desire for institutions that can articulate them.
\end{abstract}

Keywords: care ethics; Hans Jonas; intergenerational ethics; responsibility; risk; uncertainty

\section{Introduction}

Responsibility is a multifaceted condition that always achieves expression within a social and institutional context. This context constrains and enables the processes through which responsibility is articulated by, amongst other things, fixing its relationship to time (Ingarden 1970, 5-34; Birnbacher 2003). For example, we can be held responsible for our deeds after the fact (expost) as their negative consequences emerge, and we can then take responsibility for what we are accused of by making socially appropriate reparations. But we also take responsibility actively before the event (ex ante) in different social contexts: leading work projects, making promises, caring for our children, and instigating activist groups. In this way, the ethical and political significance of actions is dependent upon the background of social practices against which their impacts upon the lives of others become visible.

For most of human history, this social backdrop of responsibility extended the scope of obligations only as far as our neighbours. However, in a world where links between individuals and groups are increasingly global, the ethical significance of others in distant countries is becoming a concrete reality (Young 2006, 102-3). With this extension in space has also come extension in time. The face-to-face context which once formed the basis of the spatial and temporal framework within which actions and consequences had significance has now been overlaid with one in which advanced technology extends the temporal reach of the consequences of action even into the distant future (Jonas 1984, 4 12), through its power to affect the macro and microstructures of both human societies

*Author email: grovesc1@cf.ac.uk

Original is available at http://www.informaworld.com DOI: $10.1080 / 17449620902765286$ 
and the planet's biosphere. Against this changed 'timeprint' of human action, the ethical significance of future generations and non-human entities requires clarification, given that the consequences of actions can have impacts which are systemic and that take generations to become apparent (Adam and Groves 2007).

This need is made more urgent by growing awareness of how our preoccupation with obta ining quantifiable economic benefits here and now obscures a critical social deficit. This deficit is an increasing gap between the power of our social and technological capacities for decisively changing the future on a massive scale - not only for potent ial humans, but for nature - and our diminishing capacity to both comprehend the ethical significance of this power, and to develop institutional structures that would reflect and embody such an understanding (Lenk 1997, 103; Adam 1998; Pellizzoni 2004, 553). In the words of Hans Lenk $(1997,104)$, '[w]e seem unaware, incapable of implementing the responsibility required for the overall functioning of ecosystems in general'. Our overriding concern is, instead, with emptying and commodifying the future, and developing financial tools for transforming it into a source of economic value in the present (Green 2000; Hardt and Negri 2000, 272; Groves 2007).

In the face of this structural irresponsibility, rooted in the interdependence of economic imperatives and technological practices (Beck 1992), it is arguable that ongoing discussions of cosmopolitanism need to be complemented by a debate about what one writer has called 'chronopolitanism' (Cwerner 2000). This would recognise that not only are the lives of spatially distant contemporaries strongly interwoven, but in addition the ethical significance of present actions cannot be understood without considering their impact on future generations and on the future of non-human entities.

One outcome of this debate might be agreement that there could be no valid way of distinguishing between the ethical statuses of two individuals based solely on when they are born (Kavka 1978, 188). Consequently, economic practices such as futurediscounting would be worthy of condemnation (Parfit 1983a, 31). Following this principle, Galen K. Pletcher (1981) has defended the view that future persons can, without contradiction, be said to have rights, despite not yet existing. Not all our obligations, notes Pletcher, are to particular others. ${ }^{1}$ Some of them are prescribed by 'rights-functions' which have no specific beneficiary in mind (Pletcher 1981, 168) - for example, if I leave broken glass in the undergrowth, this is still morally wrong, even if the child who is eventually injured by it has not even beenborn when I leave it there (Parfit 1987, 356-7).

I will argue that, for two reasons, this view of future-oriented obligations is not sufficient to remedy the above-mentioned social deficit. I will further argue that an adequate remedy requires that we move away from any view that individual rights are the foundational currency in which the ethical significance of future generations can be fully cashed out. First, the diverse kinds of uncertainty surrounding future effects of some technologies present an epistemological and, moreover, an existential problem that undermines the value of the rights-functions into which Pletcher translates our duties to future people. Second, the necessarily individualistic nature of the ascription of rights 
means that a framework based on them cannot adequately address the systemic impact of our actions, particularly insofar as the consequences of these actions result in harm to our supporting ecosystems and the non-human entities that participate in themalongside us. The boundary that the consequences of an action needs to cross in order to become defined as harmful, and thereafter as wrong, is not adequately defined by the boundaries which are set out as fundamental to any definition of moral wrong by theories of rights. If the language of rights is useful in this context, then it will be as a complement to a different understanding of the nature of responsibility, one derived analytically from the kinds of obligation associated with social practices of non-reciprocal caring (Callahan 1971; Jonas 1984), rather than one which reflects the kind of reciprocal obligations that derive from natural rights. Whereas the affirmation of rights emphasises the separation between individuals, an analysis of the structure of care affirms their connectedness. As a result, the ethical considerability of future people and of the ecological support systems with which they are inextricably linked follows from the form of valuing that is articulated through care.

\title{
The irreducibility of radical uncertainty to risk
}

\section{Consider this scenario:}

\begin{abstract}
(A) A company develops a new and highly effective synthetic chemical for pest control which becomes the market leader. Early tests on the product indicated that it was safe when used in typical agricultural settings, employing tried and tested safety procedures supported by the most advanced scientific knowledge available at the time. But thirty years later, it is discovered that small residues of the chemical have been incrementally accumulating in the bodies of animals and humans outside the areas in which it is being used due to some unknown transfer mechanism, and that the occurrence of certain birth defects and degenerative diseases has increased in the period since its widespread adoption.
\end{abstract}

Such problems have proven disturbingly common in relation to advanced chemical, genetic, bio-, and nuclear technologies, and are a major concern in debates over the development and regulation of nanotechnology (Wetter 2006). By using products based on these technologies, we introduce them into social and ecological relationships in which unpredictable and uncontainable contamination can potentially occur. Crucially, these unintended consequences can remain latent for generations, and are often multi caus al (Gofman and Tamplin 1979, 95-6; Colborn et al. 1996; Adam 1998, 165-6; Koppe and Keys 2001). The problem here derives, in the first instance, from the very novelty of the technologies. The consequence of utilising fundamental natural processes (relationship between genotype and phenotype, nuclear fission, formation of chemical bonds, etc.) outside the systems in which they are embedded and for externally assigned ends takes us beyond a laboratory situation in which probabilities of unwanted events can be assigned with high degrees of scientific certainty. Instead, we are confronted by complex, singular situations whose broader outcomes generally remain very uncertain (Kaiser 1997, 201). Because the conjunctions of means and ends created by technology are absent from nature, there is no accumulated corpus of data by which to judge their effects 'in the wild', meaning that the probability of risks which can be identified cannot 
necessarily be estimated. Beyond the region of specifiable probabilities of harm, we are in the realm of scientific uncertainty or ignorance, which means that the possibility of unknown and extremely serious risks must always be considered (Hansson 2005, 73-8). The resulting situation is often one in which the capacity of a technology to produce harm cannot be judged before its widespread use, turning the outside world into an extension of the laboratory (Gofman and Tamplin 1979; Krohn and Weyer 1994). In such cases, the context of action is often one where ignorance, rather than risk, has to be a key factor in decision making (Wynne 1992; Beck 1996; Hansson 1996; Gross 2007).

That scientific ignorance is implicated in the social diffusion of new technologies is particularly significant because, in both moral and legal contexts, responsibility can typically be avoided if it can be shown that all possible measures for avoiding harm, based on then-current knowledge of the risks of action, were taken. Therefore, if certain risks were not predicted at the time of acting due to the state of knowledge at that time, the agent who committed the act can escape being held responsible for the unforeseen effects (Lenk 1997, 105; Pellizzoni 2004, 552). ${ }^{2}$ The practices by which legal and/or moral responsibility are established typically locate responsibility as a condition that obtains after the fact - that is, once the bound ary between harm and harmlessness is crossed. But in situations like (A) above, this temporal orientation tends to undermine judgements of liability: not only is the appeal to then-current scientific knowledge possible, but it also becomes difficult to establish causal authorship of harms where causal relations are multifactorial, complex and temporally extended (Jacob and Walters 2005). These considerations mean that the global uptake of what we could call (A)-type uses of technologies renders insufficient the defence of future-oriented obligations offered by Pletcher. This is because for (A)-type practices the relationship between present acts and future harms cannot always reliably be established and, indeed, actions can appear entirely benign based on what is known from past experience. Obviously there is always some uncertainty pertaining to the future impact of human actions (Arendt $1988,183-4)$. Nonetheless, technologies of this kind by their very nature extend the degree of this uncertainty by changing the object of knowledge, rather than simply augmenting the risk of already-known processes producing harm (Schummer 2001, 111).

Because the outcome of processes such as the one set out in (A) are the subject of scientific ignorance, they cause problems for the practices of traditional risk analysis (Hansson 2004, 27). This is where they differ from Pletcher's and Parfit's examples of a possible but known future harm whose probability is uncertain. The harm that may be caused by broken glass in the undergrowth is of a well-defined event-type and its occurrence connected to an equally well-defined possible event-chain. Further, the potential for harm can be unproblematically attributed to a particular thoughtless act and a particular object, even though the probabilities of someone with bare feet happening upon the glass might not be available. The uncertainties which surround the kinds of technologies we are addressing here do not belong to the same category. Not only are their potential harms of unknown scope (potentially affecting humans, non-humans and ecological relationships) and the causal mechanisms by which they may be transmitted unspecified, but the ultimate agent of harm maynot be a single product, as the product in 
question may enter into synergistic relationships with other substances, with these relationships then subsequently generating harmful effects. These unknown risks are characterised by time-space distantiation (Giddens 1984), as well as potentially possessing the capacity to interfere with complex systems in balance (Hansson 1996). Ultimately, the kind of uncertainty involved here is not epistemological, but existential (Dupuy 2007, 240). It is a condition of radical indeterminateness (Wynne 1992) that derives from both the temporality of human existence and its embeddedness in complex systems.

\section{Harm defined by social contracts between individuals}

In trying to disentangle the inadequacies of traditional concepts of responsibility when confronted with the radical indeterminateness of the future, our first task is to ask whether the kind of concept of harm presupposed by Pletcher's defence of rights is adequate. Much debate on issues of intergenerational equity has concentrated on the rights of future generations, in both the negative and positive senses: rights not to be harmed, and rights to particular resources. What I want to suggest now is that a rightsbased conception of justice is problematic, given the context of uncertainty and complexity to which future-oriented ethics has to extend. Its insufficiencies derive from how theories of rights establish boundaries between individuals as the primary means of defining what is and what is not harmful. The emphasis on rights is unhelpful for debates over the ethical significance of future generations given that, paradoxically, the focus on separate individuals as the foundation of the moral order makes it harder to understand how harms can be visited on individuals distant in time. ${ }^{3}$

In reflecting upon the social background of responsibility, political philosophy has often referred to the concept of a social contract that is logically presupposed by the structures of political and legal authority which regulate social institutions. A typical formulation is Locke's:

And, being furnished with like faculties, sharing all in one community of Nature, there cannot be supposed any such subordination among us that may authorise us to destroy one another, as if we were made for one another's uses, as the inferior ranks of creatures are for ours. (Locke 1993, 117)

In the Lockean natural law tradition, the condition of equality between moral agents obtains independently of socio-legal arrangements, and thus provides a standard to which they should conform. The crucial elements of this standard relate to the possibility of harm, and establish the moral basis both of individual action and of legal institutions. If there is no natural reason why any individual should possess a lesser moral status than any other, then certain reciprocal responsibilities exist between individuals who are capable of harming each other. The basis of a social contract, and of all social practices, is therefore held to be mutual and reciprocal restraint.

For this condition to operate, it is necessary that individuals take responsibility for their actions. Individual moral autonomy, interpreted as the active recognition of a Lockean law of nature, is therefore presupposed by a functioning social contract and is prior to all social practices by which responsibility is articulated. Autonomous individuals express 
respect for the ethical integrity of others, refraining from trespassing against their just entitlements. Such a concept of a social contract is therefore the basis of both will (or choice) theories and interest theories of rights.

These entitlements themselves derive from the basis of autonomy - namely, the capacity to have chosen to act otherwise than one actually did (Chisholm 1967). This power to either act in one of a number of specific ways or refrain from action ultimately inheres in the ability to decree for oneself a rule of conduct and follow it out of free will (Kant 1993, 40-1). The constitutive functions of moral agency enable actions to be explained by reasons as opposed to causes, and are held within liberal democratic traditions of political thought to be the source of the equal intrinsic value of individuals (Korsgaard 1996).

A social contract that protects either the interests or choices of individuals is therefore an articulation of their fundamental equality. This contract is extended by Pletcher into the future, theoretically making it 'time-blind', as well as blind to differences between classes, races, genders, sexual orientations, and so on. A social contract defines harm in relation to the responsibilities individuals have to protect choices or interests. The rightsfunctions of which Pletcher writes therefore specify rights which apply to actions that may affect the choices or interests of one or many unspecified persons, alive now or who may yet be born. In this regard, it is not important that future generations do not yet exist, and can therefore neither claim anything for themselves nor appoint someone else to exercise or defend their rights for them. What is important for Pletcher is the predictability of harms occurring in the future. Consequently, the most common forms of objection to the idea that future generations have rights (e.g. de George 1981, 160; Macklin 1982 Q5 , 152-3; MacLean 1983, 183-4) are lacking in substance in view of Pletcher's defence, at least when it comes to acts in the present which are liable to directly harm the freedom of future generations to pursue their interests.

However, the kinds of actions we are interested in here are ones where the predictability of harm cannot be relied upon, and are also ones that characterise the global conjunction of economic imperative and technological practices. This is because causal authorship is not determinable in the way it is where, for example, I drop broken glass in the undergrowth. Here, a specific instance of my agency brings about a well-defined risk of well-defined consequences. The crispness of these definitions is based on publicly verifiable knowledge of causal relationships derived from a wealth of past experience (broken glass can cause injury) and on my decision to ignore this knowledge and throw the glass away anyway. It is also refers back to the sharp boundaries around individuals that social contracts are supposed to make possible. Together, the causalknowledge, the knowledge of agency, and the knowledge of the relationship between these factors and the boundaries between individuals make me culpable should I act in a way which ignores them.

In example (A) above, however, the possibility of a specific harm occurring was unknown, but was nevertheless rooted in the nature of the technology being used, together with the economic imperatives that encouraged its widespread deployment. 
Where such harms are caused, they are often the result of a long-term destabilisation of ecological relationships that tie together humans and non-humans (Hansson 1996). The future-oriented irresponsibility - the denial of connection between acts and harms potentially present in the development and use of such technologies does not therefore derive from the same source as in Pletcher's examples. Although those eventually suffering harm will include individual humans, the harm caused to them would be propagated as a result of inevitable non-knowledge (Schummer 2001; Gross 2007) rather than of disregarded knowledge, and the processes by which it would be propagated would be complex, systemic and temporally extended. In this context, the idea of a social contract in the Lockean sense does not capture the connectedness of act and harm.

\section{The temporal context of action}

It is increasingly argued that in a world where social action reveals to us the multi-level interconnectedness of individuals, moral concepts based on assumptions of their essential separation, such as the Lockean social contract, need revision. Iris Marion Young has suggested that the lives of contemporaries are connected through such complex mediating webs of social relations that the direct causal authorship model of responsibility must be supplemented with one based ona distribution of benefits and harms, in order to grasp the connection between, for example, patterns of consumption in the USA and the conditions of sweatshop workers in the Philippines. Consequently, 'all agents who contribute by their actions to the structural processes that produce injustice have responsibilities to work to remedy those injustices' (Young 2006, 102-3). Nonetheless, Young's extension of the concept of responsibility relies on our knowledge of specific global interconnections between social practices and harms. Although she remodels obligations by considering their changing social background, Young argues our primary responsibility is to remedy our ignorance of hitherto unknown causal connections. As Aristotle noted, we can be held responsible for things we do not know if we have not tried to discover them. Responsibility is based, once again, on knowledge of what has already happened and continues to happen in the present. Where not just systemic complexity but also space-time distantiation and the production of non-knowledge are factors, a different approach is needed.

What is required is a recognition of responsibility that consistently carries through the intuition of Hans Jonas (1984) that future-oriented responsibility, particularly in contemporarysocieties, is primarily non-reciprocal. It is not a matter of reciprocal avoidance of harm, or extending this principle into situations where actions could hurt other unspecified or even not-yet-existent individuals in predictable ways. Instead, it is about avoiding kinds of harm which are inherent in contemporary forms of social practice and which, while ultimately encompassing in their effects the fates of individual humans, achieve these effects by altering fundamental socio-ecological relationships.

Jonas notes that the idea of individual responsibility under a social contract aims to establish, above all, limits under which actions become imputable after the fact to specific individ uals.

Behind this idea is the assumption that social order depends on the capacity to reliably establishcausal relationships between acts carried out by one individual and the 
consequences experienced by her close contemporaries. If the effects of one's deeds are largely limited to those with whom one immediately shares public space, then certain specific concepts of duty, blame and liability are required, and this requirement is reflected in Hellenic republicanism and Lockean liberalism alike. However, in the contemporary context, different principles have to apply: '[w]hat will happen to that being if I do not take care of him? The more obscure the answer, the more clearly delineated is the responsibility' (Jonas 1984, 285). Scenarios like (A) above show that the necessary obscurity of the connection between acts and harms is central to the contemporary problem of responsibility. This problem depends not upon an adventitious lack of knowledge, but rather upon an inescapable ignorance (Dupuy 2007, 240).

\section{Future-orientation and care}

A chief problem of future-oriented ethics is therefore how to deal with the inherent uncertainties resulting from social practices like technological innovation. It is not necessarily the identities of future people and the boundaries around their interests and choices which form the centre of the problem, but the possibility that action in the present will destabilise the systems on which they depend, together with the obstacles this places in the way of agents having the foresight and motivation to act appropriately. This means that an ethics with systemic scope and which gives a suitable account of motivation would be extremely apposite. I will argue now that the focused integration of concepts of care into the vocabulary of intergenerational justice might assist in this endeavour.

Care links moral psychology and development with the scope of ethical considerability in a unique way: it "sheds light on how the emotions enable us to "enter" the moral domain, but also to create it and extend it' (Leccardi 2006, 17). The development of care-based concepts of ethics by feminist theorists has expanded accounts of moral cognitive processes beyond narrow concepts of practical judgement that define it as the application of general principles to particular situations. As such, it is linked to contemporary attempts to articulate moral agency along the lines of an Aristotelian conception of phronesis (Nussbaum 1990). Nonetheless, a commonobjection to care ethics concerns its focus on particularity and especially individual experience at the expense of universal normative concepts, suggesting that its concern with the emotional content of moral subjectivity leads it away from universality, and disables moral judgement in the process (Kymlicka 2001). In the context of the problem we are addressing, this objection appears particularly serious, given that future-oriented ethics appears to be addressing the most impersonal domain imaginable, one of systemic relations that include but extend beyond the currently existing human moral community itself.

However, I shall argue that this is mistaken. The aforementioned objection to care ethics appears to assume that there is a necessary distinction within ethics between the particular and the general, or between the situational and the universal, and that by concentrating on the first term of these oppositions, we lose our ability to ascend towards the second. However, ethics is arguably faced with a perpetual task of bridging the gaps between the terms of such oppositions, by understanding the relationship between the motivational bases of ethical behaviour and the general principles that are taken to have 
sufficient authority to guide it. Kant's maxim can be adapted here: to assume that ethics should only articulate how an ideally moral person should behave risks rendering ethical thought empty and impotent, while to assume that the real subject matter of ethics is the structure of moral feeling risks making it blind and arbitrary. To take care as the basis of understanding normativity might be one way of getting over this duality.

It is arguably true that to articulate care as a situational experience of ethical behaviour has been a dominant tendency in the literature on care ethics. But care implies also a particular way of reasoning about the nature of the connections between carers and the cared-about. In other words, there is a logic of care: understanding the structure of this logic can perhaps unite the particular with the general, situated experience with normative judgement, and care with justice. ${ }^{4}$ An analysis of care is particularly useful for our purpose here because the structure of care is irreducibly temporal and concerned with the futurity of concrete situations, and these situations are by no means limited to face-toface encounters. By looking at how care, as a socially oriented existential capacity, constructs its objects, we shall see that this analysis produces both a specific way of understanding moral judgement, and general principles of conduct. An account of responsibility based on the structure of care can give us both an understanding of what motivates ethical concern, and principles to guide it. It can also help us to understand what people objectively have in common, no matter where or when they exist,5 and to what extent this commonality can serve as an ethical principle.

Care has been a major concern for both phenomenological and feminist thought, in different senses. What nevertheless links these traditions of thinking about care is the temporality they both ascribe to it. The concept's phenomenological heritage is one that ultimately links it with the scholastic idea of conatus. For example, Heidegger describes care (Sorge) as the 'totality of being-in-the-world' (Heidegger 1998, 182), that which characterises all humandealings with the not-self, a concern for what significance things have in relation to 'my projects' ${ }^{6}$ Care is thus a way of conceiving of human self-concern as inherently futural, as bound up with the potential things have for making my projects turn out well or badly. The meanings with which things and people come loaded are inseparable from the 'fringe' of pastness and futurity they bear. In this regard, care is an extension of how Jonas (1982) interprets conatus, as a motive force of self-concern that plays a constitutive and not merely receptive role in defining and interpreting the environment of an organism, utilising the cognitive capacities (including feeling and emotion) with which organisms of varying degrees of constitutional complexity are differentially endowed. In this sense, our understanding of what our interests are is inescapably temporal and partial. Our interests are not simply given to us, but are instead projects whose singular meaning changes over time, constituting a narrative of development.

Care as a phenomenological structure of human experience therefore implies a different model of subjectivity to the 'rational actor' typically assumed in economics and much liberal political philosophy, whose interests are more or less fixed. The feminist sense of care, which feeds into 'care ethics' more widely construed, begins from different foundations, but also describes human subjectivity as bound up with a temporally 
extended concern with the world, only here this world is affirmed as being irreducibly socially mediated (van Hooft 1995). For care ethicists, to understand the structure of care is not possible without understanding the processes through which attachments and commitments are formed.

This implies that the role of the emotions in psychological development and moral judgement must be investigated, as well as the conceptual bases under which commitments may be compared and prioritised and which form the more familiar subject matter of ethic s. Ethical life is seen as not being possible without connectedness, conceived of as an active capacity for dedicating oneself to particular values, such as another person, a way of life, a moral principle, or a goal (van Hooft 1995, 15-19). There is therefore not only a developmental relationship between attachment, meaning and agency (Stern 1985; Benjamin 1988, 94-6), but also an ethically constitutive one, in the sense that these three elements determine the context of moral action and give impetus and direction to judgement. For care ethicists, agency is unthinkable without commitments, which develop outwards through our interactions with others: in becoming an ethically capable subject, we become 'an individual with a concrete history, an identity, and an affective-emotional constitution' (Benhabib 1992, 159). We discover the significance of our acts through our affective, imaginative and cognitive connections with other concrete individuals. We discover the projective and agentive character of our lives in and through others with whom we recognise we share acommon destiny. Our affirmation of such a destiny implies that our sense of who we are and what we have done is bound up with how we interpret and evaluate the identities, biographies and intentions of concrete others. Our everyday lives are framed by a range of affective and cognitive connections with the fates of others, from which their significance is woven.

Responsibility, in the sense of being called upon to respond, is first encountered within this context of action. Empathy with the other calls us to action (Ricoeur 2000, 28-9; Leccardi 2006). In this sense, responsibility answers a call to extend one's sphere of action rather than a demand to curtail it in the face of another's rights (Gilligan 1982, 38). 7 This primary ethical context is one where the urgency of the demand expressed in the face of the other (Levinas 1969, 200) requires of us a non-reciprocal responsibility to attend to their needs. Particular others become our teachers in responsibility. We are trained by them in the skill of fitting particular ethical judgements to novel circumstances, all within the context of our evolving biographies. It is by responding to the complex needs of friends and family members that we learn we cannot escape the call of responsibility in the face of suffering, and yet our response is difficult thanks to our finitude and the limits of our capacity to act out of care for others. Nonetheless, it is by negotiating this difficulty that we are able to improvise moral responses both within familiar groups and in contexts which, as we grow up, are marked more and more by encounters and interactions with groups of strangers. Our understanding of ourselves is thus a relational one: we experience agency as caught in tension between particular commitments and the capacity to reorder, judge, prioritise, renounce and renew them. 8 But there is always a vital tension here: these particular commitments are never easily replaceable. This is because the value of particular commitments lies in how they confer meaning. We come to see them as ingredients of the particular narratives that make up 
lives. Our experiences of others to whom we are committed are therefore ones of individuals who are constitutively valuable. We find their well-being and flourishing to be inseparable from our own, and therefore find their existence to be a constitutive condition of the meaningfulness of our own lives (O'Neill 1993, 24). To flourish as ourselves, we require just as much that they flourish as themselves. It is at this point that we can trace once more a connection between phenomenological analyses of care and those provided by care ethicists, via the temporality which is inherent in concepts like 'well-being' and 'flourishing'. The ways in which concrete others matter to us are inseparable from how things will turn out for us separately and together. The future, as the horizon of care, cannot be identified with the open space beyond the present which the 'first modernity' of social progress (Beck 2005, 3-4) uses as its primary organising image of the future, or the entirely empty future of economic calculation (Adam and Groves 2007, 71-5).

The future is not untenanted: it is full of the latent, singular fates of our commitments (Rolston 1981, 124), which grasp at us with more or less intensity as we extend ourselves, through empathy, imagination, and rational deliberation, towards them. The future is always the future of what we care about and within which the objects of care will flo urish or decline (Passmore 1974). As such, it is the source of the call our commitments make upon us, and of agency itself.

\section{Care and impersonal future-oriented responsibilities}

Caring is, first and foremost, a process through which I and others develop to gether capacities for perceiving, judging and acting. These capacities are predicated upon a specific logic of responsibility, one based upon taking up a non-reciprocally responsible position towards whatever is cared for. In terms of different temporal modalities of responsibility mentioned at the very beginning of this article, their primary aim is to handle the world responsibly, by being responsible to the potential of relationships. Although they may aim at specific ends, their primary end is to help sustain the capacity of a relationship to become, for new actualities to emerge from within its potential futures. Part of the significance of these capacities is that they recognise the irreducibly futural temporality of the relationships with which they are concerned. Just as the sensitivity of an artisan to her material enables her to feel the potential significance of the traits it already contains, so emotional identification with the relationships through which a situation is defined enables us to respond to the salient aspects of its developing ethical 'shape' (Nussbaum 1990, 79). The attitude of the artisan demands and supports improvisation in the face of unknown discoveries (Protevi 2001). The attitude of care centres on the capacity to improvise a response to the hitherto unforeseen and the entirely unforeseeable, and thereby to preserve a commitment in the face of uncertainty without resorting to the false certainty which would be provided by articulating this commitment in terms of an abstract rule (Nussbaum 1990, 94).

Let us now consider how care, in this sense of concern for singular futures, extends us beyond the realm of face-to-face relationships. Our commitments are not exhausted by these relationships. We also find ourselves becoming deeply committed to the 
preservation of the well-being of many non-human objects. Nonetheless, the value of these objects for us is of the same form as that of concrete human others. Things (such as landscapes or artworks), institutions (such as a democratic constitution) and ideas (such as liberty or identity) are three examples. Independent of any instrumental value, such 'individuals' can be judged to have a many-sided potential for contributing to meaningful lives. As a result, their own flourishing is of non-reciprocal concern to us. A landscape may be protected from attempts to reduce it to something purely of instrumental value, for example, by quarrying it. A collector may refuse to sell a painting because of its value for her as an object of contemplation or as representative of a living art tradition.

Our relationships with such objects are sometimes as concrete as those with people, having integrated emotional, imaginative and intellectual dimensions. It is felt that things can go badly or well for cared-for objects, and that their fate is bound up with ours. If things turn out badly for them, we can feel diminished as a result (O'Neill 1993, ch. 2; Schollmeier 1997). It is the capacity of such objects to have their own singular futures that makes them into reserves of meaning for us. Like ourselves, they project themselves ahead, share a temporally bounded fate, and thus have needs that must be met in order for them to flourish. Once we acknowledge that the domain of objects of care extends further than just other particular humans, it becomes necessary to recognise that the fates of different objects of care are interconnected. We thus return to the theme of a common destiny. Caring for the needs of our constitutive values necessarily leads us into an ongoing project of building up and buttressing on all sides our particular devotions with broader commitments to principles, beliefs and modes of action. The structure of what we called the primary context of caring thus implies a wider ethical logic of care.

For example, to care about a loved one means being committed to how they are looked after when sick. This might then lead us to campaign for public provision of healthcare, to join a political party, and so on. Caring as practical judgement about what is demanded of us thus necessarily involves us in both instrumental reasoning and action, and in making further judgements about what other things are constitutively valuable. As a result, we have to extend ourselves in space and time to cultivate new relationships, which may lead us to revisit and revise our previous commitments. In extending care, we increasingly have to assess, based on experience, the evolving systemic relationships between plural values over time.

The plurality of objects to which we become committed leads us to acknowledge that, thanks to their position in a system of values, many of the things we care about are valuable not just for the well-being of one single individual, but for individuals more generally - encompassing others we concretely care about, and strangers we have never met. Care thus tends to link the private with the public, sometimes in unexpected ways, rather than keeping them separate. Further, it leads us to gradually move towards a multilevel view of how our constitutive values fit together, and how the relationships between them can be understood. From individual people, we move to an intersubjective context; from this, to a social, institutional and historical one. From there, as our contemporary situation makes clear, we must move to an environmental and ecological one, as we 
recognise that the constitutive value of the natural world is an ingredient of our own flourishing.

Consequently, care opens onto an uncertain future, but it does not thereby paralyse us and remove any motivation to act responsibly. Although it does not make the future any more predictable, it nevertheless provides us with opportunities for training ourselves to respond creatively, flexibly and (hopefully) consistently to its unpredictability, by recognising that we, no matter what we do, are inextricably linked to near and distant futures through the activities through which we realise our care and thereby make posterity. It is the particular constitutive values to which we are committed that enable us to navigate our way. Further, if our own flourishing is bound up with the things, people and ideals to which we are committed, then there is a sense in which our lives can be said to continue to go well or badly even beyond our own deaths through what happens to these constitutive values. The future beyond the limits of our own mortality, embodied in what we find constitutively valuable, will objectively transform the meaning of our lives, and this objective situation influences our own agency. If we became convinced that our grandchildren would be forced to live on an earth devastated by war or global warming, then our own lives now would fall under a shadow. Similarly, if I am a scientist, and were to become convinced that such a future would mean that scientific knowledge itself would largely vanish, then I would also feel diminished by the prospect. In this sense, it follows that how even the distant future turns out can affect the value and meaning of our own lives (O'Neill 1993, ch. 3). In caring about the future, we extend ourselves beyond concern for those alive now to 'anticipate' the care of others for their world (Passmore 1974). The stronger this sense of participating in projects whichconnect us with future generations, and therefore the sense of sharing a narrative with them (Rolston 1981), the stronger our sense that near and distant futures both matter to us now.

\section{Conclusion}

Do we have, therefore, a duty to care about the future? What I have argued here is that the experience of caring is the root of ethical behaviour - that is, acting in ways which value others in themselves. Further, as feminist analyses of care point out, valuing another for herself is also to value one's relationship to her. And as both feminist and phenomenological concepts of care suggest, care is always care for what this relationship is becoming. I have also argued that these considerations imply that care for individuals necessarily leads to the adoption of more general principles in order to safeguard what or whom we care about:

Principle 1: We have to act so as to preserve and enhance the potential of what we find valuable, where 'valuable' means of value both to the flourishing of specific individuals living now and to the flourishing of individuals generally now and in the future. Here, we must emphasise that acting to preserve and enhance what we find valuable obligates us to investigate the relationships that sustain these values, and to act so as to sustain these relationships in turn, as far as possible.

Principle 2: We need to act so as to preserve and enhance the capacities of future generations to care as such. The ultimate principle of care is therefore the 
imperative identified by Hans Jonas: 'never must the existence or the essence of man [sic] as a whole be made a stake in the hazards of action' (Jonas 1984, 37). We need to act towards the future with the aim of sustaining the particular narratives which make the world meaningful for us, and of sustaining the possibility of experiencing such narratives at all. We should act not only to preserve our constitutive values, but also to preserve the capacity of future humans to care about things in their own way, and to thereby revise the assessments of what is constitutively valuable that they have inherited from their predecessors.

In this article I have not therefore tried to merely indicate that care as a motivation is genetically the ground of more principled forms of moral reasoning. Rather, my analysis of the structure of care leads to two conclusions.

First, as the type of beings whose relationship to the world and to other beings like ourselves is typically one characterised by care as I have described it, we should seek to protect the future from outcomes of the kind that occur in scenario (A) above. This justifies a qualified precautionary approach to the development of new technologies, although this must be substantially different from existing qualified applications of the precautionary principle. Current precautionary approaches to technolo gical innovation in the EU, for example, operate as an extension of formal approaches to risk analysis. They typically view precautionaryaction as only justified by the possibility of quantifiable damage to human health or the environment. Further, they view precautionary measures (which must be 'proportionate' to the possible harms) as temporary interruptions, which can be rescinded once a higher degree of scientific certainty about the absence of specific risks has been attained. ${ }^{9}$ Precautionary approache s therefore do not touch on the economic and wider social imperatives that condition how technologies develop, and nor do they take seriously the view (discussed in the section entitled 'The irreducibility of radical uncertainty to risk', above) that uncertainty is an inevitable product of technological innovation, rather than a temporary obstacle to it (Dupuy 2004). They act only as a 'downstream' brake on innovation when certain kinds of possible harms give cause for concern. To take a genuinely precautio nary approach to technological innovation would require a substantive critique of the purposes which technologies are intended to serve, and with it, a critique of the social imperatives which ensure that (A)type scenarios will tend to proliferate. This is where the care-oriented view of obligations to the future takes us - towards a substantive understanding of precaution, based on the need to preserve and sustain the future potential of the sets of constitutive values to which we are committed. This conclusion opens up various avenues of further work. I will mention two here. First, there is the question of the institutional arrangements that would be required to set up a democratic system for establishing informed consent across society to specific technological developments (Shrader-Frechette 2007). The promotion of specific rights to participate in governance of scientific research and technological development would no doubt be important, and these would have to rest on a presumed right to knowledge, and the right to act upon that knowledge in pursuing substantive social goods (Tallacchini 2004, 650). Equally, the promotion of group or individual rights for non-human entities might become a necessary part of the institutional context. The second conclusion concerns what substantive social goods should be pursued. Because the future is ultimately our source of constitutive value, we should aim to meet 
its projected needs as far as possible. To set out what these needs might be, we have to begin with what we know about the needs that have to be met here in the present. This means that we will need to decide between competing sets of constitutive values which are the subject of Principle 1 above, and also between competing assessments of what is needed in order to sustain them. However, with respect to Principle 2, there is perhaps more immediate room for agreement about future needs (Hansson 1996, 384), a point which is central to theories of development such as that presented by Manfred Max-Neef (1992). It may be that the requirements of Principle 2 will constrain what is desirable under Principle 1, as they will inevitably require judgements about quality of life and about the nature of sustainability.

I have not tried to show in this article that something like a universal experience of caring can somehow lead us to care directly about the distant future. Rather, I have argued that because we care here in the present about diverse things on their own account, it is rational that we should care about the future as the 'place' where the fates of many of these diverse things will continue to be played out in ways we cannot imagine. Further, because to care about the fate of one thing necessitates caring about the fate of other things, we are required to promote the well-being of the networks of social and extrasocial ecologies within which the things we care about are rooted, and for this we require both the skill to make situated judgements and some general principles to guide them. Our necessarily local and situated concern for constitutive values contains an internal logic which demands it expand itself further, both spatially and temporally, to touch distant others, the non-human world, and future generations.

\section{Acknowledgements}

I would like to thank Professor Christoph Rehmann-Sutter, an anonymous referee and Professor Robin Attfield for their helpful comments on an earlier version of this article, which is based on research conducted in the School of Social Sciences at Cardiff University on the ESRC Professorial Fellowship In Pursuit of the Future (RES051270049).

\section{Notes}

1. Contra the position that we can only have obligations to particular others, advanced by, for example, Thomas Schwartz (1978).

2. For example, in the European Union (EU) a limitation of this kind on strict product liability (the so-called Development Risk Defence) is set out in Article 7(e) of Directive 85/374/EEC (EU Council 1985), which has been adopted and transposed into law in all EU countries at the present date except Finland and Luxembourg. The Consumer Protection Act 1987 is the relevant UK legislation. It has been suggested that removal of the defence would represent a threat to technological innovation and consumer confidence (Clarke 2004, 2).

3. For reasons of space, I do not consider here in detail arguments about the possibility of extending rights to non-human entities, whether taken individually or collectively, of the type advanced by Stone (1972). However, the concept of harm implied in such arguments is arguably 
related to the concept of harm I criticise in this section. I briefly consider what the proper role of rights might be in relation to a future-oriented ethics in the conclusion.

4. For a different approach to overcoming this duality which is informed by care ethics, see Friedman (1993).

5. Cf. Kavka 1978, 190-1.

6. Projects, for Bernard Williams (Williams and Smart 1973, 116), are concerns which someone 'takes seriously at the deepest level, as what his life is about'.

7. Hence Daniel Birnbacher's $(2003,88)$ observation that limits on responsibilities to the future have to be seen in terms of opportunity costs still presupposes that the moral agency of individuals is fundamentally defined by their separation from each other.

8. As Benjamin (1988) and Gilligan (1982) note, however, this tension tends to be dealt with and resolved differently by different subjects, with gender being a major factor in the outcome.

9. The piecemeal and cautious application of the precautionary principle in the EU to date thus undermines the alarmist predictions of some commentators that precaution must necessarily lead to scientific paralysis (e.g. Holm and Harris 1999).

\section{References}

Adam, B. 1998. Timescapes of modernity: The environment and invisible hazards. London: Routledge.

Adam, B., and C. Groves. 2007. Future matters: Action, knowledge, ethics. Leiden: Brill.

Arendt, H. (1998). The human condition, Chicago, Chicago University Press.

Beck, U. 1992. Risk society: Towards a new modernity. London: Sage. . (1996). Wissen oder Nicht-Wissen? Zwei Pespektiven reflexiver

Modernisierung. In Reflexive Modernisierung. U. Beck, A. Giddens and S. Lash. Frankfurt a. M., Suhrkamp: 289-315.

2005. Neither order nor peace: A response to Bruno Latour. Common Knowledge 11, no. 1: 1-7.

Benhabib, S. 1992. Situating the self. Cambridge: Polity Press.

Benjamin, J. 1988. The bonds of love: Psychoanalysis, feminism and the problem of domination. New York: Pantheon Books.

Birnbacher, D. 2003. Verantwortung für zukünftige Generationen - Reichweite und Grenzen. In Handbuch Generationengerechtigkeit. ed. Stiftung für die Rechte zukünftiger Generationen. Munich: Ö kom Verlag.

Callahan, D. 1971. What obligations do we have to future generations? American Ecclesiastical Review 164: 165-80. 
Chisholm, R. 1967. He could have done otherwise. Journal of Philosophy 64: 409-17.

Clarke, M. 2004. The future of the development risk defence in Europe. Ashurst Product Liability Briefing (December): 1-2. http $/ /$ www.ashurst.com/ doc.aspx ?id_Content $1 / 41395$

Colborn, T., D. Dumanowski and J. P Meyers. 1996. Our stolen future. London: Abacus.

Cwerner, S. 2000. The chronopolitan ideal: Time, belonging and globalization. Time \& Society 9 , no. $2 / 3: 331-45$.

de George, R.T. 1981. The environment, rights and future generations. In Responsibilities to future generations. ed. E. Partridge. New York: Prometheus Books.

Dupuy, J.-P. 2004. Complexity and uncertainty: A prudential approach to nanotechnology. Paper presented at European Commission: A Preliminary Risk Analysis on the Basis of a Workshop Organized by the Health and Consumer Protection Directorate General of the European Commission, March 1-2, 2004, in Brussels, Belgium.

- 2007. Some pitfalls in the philosophical foundations of nanoethics. Journal of Medicine and Philosophy 32: 237-61.

European Union (EU) Council. 1985. Directive on the approximation of the laws, regulations and administrative provisions of the member states concerning liability for defective products. 85/374/EEC.

Friedman, M. 1993. What are friends for? Feminist perspectives on personal relationships and moral theory. Ithaca, NY: Cornell University Press.

Giddens, A. 1984. The constitution of society. Cambridge: Polity Press.

Gilligan, C. 1982. In a different voice. Cambridge, MA: Harvard University Press.

Gofman, J.W., and A.R. Tamplin. 1979. Poisoned power. Emmaus, PA: Rodale Press.

Green, S. 2000. Negotiating with the future: The culture of modern risk in global financial markets. Environment and Planning D: Society and Space 18: 77-89.

Gross, M. 2007. The unknown in process - dynamic connections of ignorance, nonknowledge and related concepts. Current Sociology 55: 742-59.

Groves, C. 2007. The humanities and the shaping of social futures. International Journal of the Humanities 5, no. 4: 49-54.

Hansson, S.O. 1996. Decision-making under great uncertainty. Philosophy of the Social Sciences 26:369-86. 
Hansson, S.O. 2004. Great uncertainty about small things. Techne 8, no. 2: 26-35.

- 2005. The epistemology of technological risk. Techne 9, no. 2: 68-80.

Hardt, M., and A. Negri. 2000. Empire. Cambridge, MA: Harvard University Press.

Heidegger, M. 1998. Being and time. Oxford: Blackwell.

Holm, S., and J. Harris. 1999. Precautionary principle stifles discovery. Nature 400, no. 6743: 398.

Ingarden, R. 1970. Über die Verantwortung. Stuttgart: Reclam.

Jacob, C., and A. Walters. 2005. Risk and responsibility in chemical research: The case of agent orange. Hyle 11, no. 2: 147-66.

Jonas, H. 1982. The phenomenon of life, Chicago; London, University of Chicago Press 1984. The imperative of responsibility. Chicago: University of Chicago Press.

Kaiser, M. 1997. The precautionary principle and its implications for science.

Foundations of Science 9: 201-205.

Kant, I. 1993. Groundwork for the metaphysic of morals. Indianapolis: Hackett.

Kavka, G. 1978. The futurity problem. In Obligations to future generations, eds R.I. Sikora and Brian Barry. Philadelphia: Temple University Press.

Koppe, J.G., and J. Keys. 2001. PCBs and the precautionary principle. In Late lessons from early warnings: The precautionary principle 1896-2000, eds P. Harremoes, D. Gee et al. Copenhagen: European Environment Agency.

Korsgaard, C. 1996. The Sources of Normativity. Cambridge: Cambridge

University Press.

Krohn, W., and J. Weyer. 1994. Society as a laboratory: The social risks of experimental research. Science and Public Policy 21, no. 3: 173-83.

Kymlicka, W. 2001. Contemporary political philosophy: an introduction. Oxford: Oxford University Press.

Leccardi, C. 2006. Rethinking responsibility: Sociolo gical perspectives. Paper presented at Cardiff University, School of Social Sciences, October 26, in Cardiff, UK. 
Lenk, H. 1997. Progress, values, and responsibility. Society for Philosophy and Technology 2, no. 3-4:102-19.

Levinas, E. 1969. Totality and infinity: An essay on exteriority. Pittsburgh: Duquesne University Press.

Locke, J. 1993. Two treatises of government. London: J.M. Dent.

Macklin, R. 1981. Can future generations be said to have rights?. In Responsibilities to future generations. ed. E. Partridge. New York: Prometheus Books.

MacLean, D. 1983. A moral requirement for energy policies. In Energy and the future, eds P.G. Brown and D. MacLean. Totowa, NJ: Rowman and Littlefield.

Max-Neef, M. 1992. Development and human needs. In Real life economics, eds P. Ekins and M. Max- Neef. London: Routledge.

Nussbaum, M.C. 1990. Love's knowledge: Essays on philosophy and literature. Oxford: Oxford University Press.

O’Neill, J. 1993. Ecology, policy and politics. London: Routledge.

Parfit, D. 1983a. Energy policy and the further future: The social discount rate. In Energy and the future, eds P.G. Brown and D. MacLean. Totowa, NJ: Rowman and Littlefield.

- 1987. Reasons and persons. Oxford: Clarendon Press.

Passmore, J. 1974. Man's responsibility for nature. London: Duckworth.

Pellizzoni, L. 2004. Responsibility and environmental governance. Environmental Politics 13, no. 3: 541-65.

Pletcher, G.K. 1981. The rights of future generations. In Responsibilities to future generations. ed. E. Partridge. New York: Prometheus Books.

Protevi, J. 2001. Political physics: Deleuze, Derrida and the body politic. London: Athlone Press.

Ricoeur, P. 2000. The concept of responsibility: An essay in semantic analysis. In The just. Chicago: University of Chicago Press.

Rolston, H. 1981. The river of life: Past, present and future. In Responsibilities to future generations. ed. E. Partridge. New York: Prometheus Books.

Schollmeier, P. 1997. Why we love the land. Ethics and the Environment 2, no. 1: 53-65. 
Schummer, J. 2001. Ethics of chemical synthesis. Hyle 7, no. 2: 103-24.

Schwartz, T. 1978. Obligations to posterity. In Obligations to future generations, eds R.I. Sikora and Brian Barry. Philadelphia: Temple University Press.

Shrader-Frechette, K. 2007. Nanotoxicology and ethical conditions for informed consent. Nanoethics 1:47-56.

Stern, D. 1985. The interpersonal world of the infant. New York: Basic Books.

Stone, C.D. 1972. Should trees have standing? Southern California Law Review 45: 45057.

Tallacchini, M. 2004. Before and beyond the precautionary principle: Epistemology of uncertainty in science and the law. Toxicology and Applied Pharmacology 207: 646-51.

van Hooft, S. 1995. Caring: An essay in the philosophy of ethics. Niwot: University of Colorado Press.

Wetter, K.J. 2006. 100 Years after the Pure Food \& Drug Act. ETC Group.

http://www.etcgroup.org/upload/publication/594/01/publicmeeting.10oct06.fda.pdf

Williams, B., and J.J.C. Smart. 1973. Utilitarianism: For and against . Cambridge:

Cambridge University Press.

Wynne, B. 1992. Uncertainty and environmental learning - reconceiving science and policy in the preventive paradigm. Global Environmental Change - Human and Policy Dimensions 22: 111-27.

Young, I.M. 2006. Responsibility and global justice: A social connection model. Social Philosophy and Policy 23, no. 1: 102-30. 